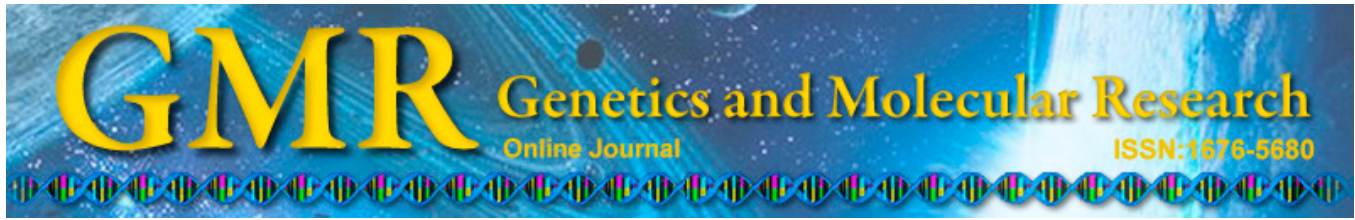

\title{
Effect of $p 53$ gene polymorphism on functions of prostate cancer cells
}

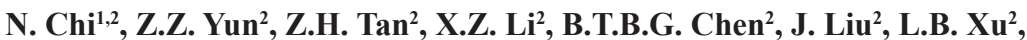
K.W. $\mathrm{Ma}^{2}$, S.X. $\mathrm{Li}^{2}$, J.F. $\mathrm{Liu}^{2}$ and C.X. $\mathrm{Liu}^{1}$

${ }^{1}$ Department of Urinary Surgery,

Zhu Jiang Hospital of Southern Medical University, Guangzhou, China

${ }^{2}$ Department of Urinary Surgery,

Inner Mongolia People's Hospital, Hohhot, China

Corresponding author: C.X. Liu

E-mail: liucxdus@126.com

Genet. Mol. Res. 14 (4): 11700-11709 (2015)

Received January 7, 2015

Accepted June 8, 2015

Published October 2, 2015

DOI http://dx.doi.org/10.4238/2015.October.2.3

\begin{abstract}
Prostate cancer cells were transfected with plasmids [empty plasmids, wild-type pcDNA3.1-p53 (V/V), mutant type pcDNA3.1-p53 (G/G)] to analyze the effect of $p 53$ gene polymorphisms on the proliferation, cycle, and apoptosis of prostatic cancer cells. Empty plasmids containing wild-type pcDNA3.1-p53 (V/V) and mutant type pcDNA3.1- p53 $(\mathrm{G} / \mathrm{G})$ were used to transfect PC3 and LNCaP cells, respectively. Cell proliferation was detected at $0,24,48$, and $72 \mathrm{~h}$ using the MTT method. Cells were collected at 24 and $72 \mathrm{~h}$. The distribution of cell cycles in various groups was detected using flow cytometry (propidium iodide staining method) and the apoptosis rate was detected using annexin $\mathrm{V}+$ propidium iodide double staining. Compared with the control group, wild-type pcDNA3.1-p53 (V/V) and mutant type pcDNA3.1-p53 (G/G) showed a significant inhibitory effect on cell proliferation $(\mathrm{P}<0.05)$; the inhibitory effect of the mutant type was stronger than that of the wild-type. There was no significant difference between PC3 cells and LNCaP cells. After transfection with wild-type pcDNA3.1-p53 (V/V) and mutant type pcDNA3.1-p53 (G/G), PC3
\end{abstract}


and $\mathrm{LNCaP}$ cells were arrested in the G0/G1 stage. Transfection with pcDNA3.1-p53 (G/G) showed a more significant effect than transfection with pcDNA3.1-p53 (V/V). Both the wild-type pcDNA3.1-p53 (V/V) and mutant-type pcDNA3.1-p53 (G/G) led to an increased apoptosis rate of $\mathrm{PC} 3$ and $\mathrm{LNCaP}$ cells. The $p 53$ gene polymorphism affects the proliferation, apoptosis, and cycle of prostate cancer cells and may serve as a reliable index for the diagnosis and treatment of prostate cancer.

Key words: Apoptosis; Cell proliferation; $p 53$ gene; Polymorphism; Prostatic cancer

\section{INTRODUCTION}

Prostate cancer is the leading cause of morbidity among male malignant tumors in European and American countries. However, with the extension of average life span and constant changes to lifestyles and dietary structures, the morbidity of prostate cancer has exceeded that of bladder tumor and renal carcinoma. Prostate cancer ranks fifth among malignant tumors in male patients and first among urologic neoplasms (Simone et al., 2013). Currently, the therapeutic regimen for prostate cancer depends on disease staging. Patients in the early or local progressive stage can be treated by radical removal of the prostate or radiotherapy. Patients in the progressive or metastasis stage may be treated with androgen deprivation therapies such as surgery or medication (Wang et al., 2013). However, most patients show a good response to androgen deprivation therapy during the first 18-24 months after diagnosis. Later, some patients inevitably show an increase in prostate-specific antigen, repeated tumor growth, and multiple osseous metastases. Next, the prostate cancer is transformed into hormone-refractory prostate cancer (HRPC) (Shin et al., 2013). No ideal therapeutic method is currently available for HRPC. Thus, studies on the occurrence and progression of prostate cancer and particularly on its disease course are important.

An increasing number of studies have shown that polymorphisms in the human genome are closely associated with the occurrence and progression of tumors. Different genotypes of the same gene may play completely opposite roles in different tumor tissues (De Luca et al., 2013). As an important tumor-inhibiting factor, $p 53$ regulates the cell cycle and induces cell apoptosis and cell differentiation (Amir et al., 2013). Therefore, polymorphisms in $p 53$ likely affect the progression and prognosis of prostate cancer. In this study, we examined the relationship between $p 53$ gene polymorphisms and prostate cancer cell cycle regulation and cell apoptosis and provide a reference for the treatment and prognosis of patients with prostate cancer.

\section{MATERIAL AND METHODS}

\section{Materials}

The human prostate cancer cell lines $\mathrm{PC} 3$ and $\mathrm{LNCaP}$ were purchased from Beijing Ruixiang Biotechnology Co., Ltd. (Beijing, China). RPMI 1640 culture medium and fetal bovine serum were purchased from Shanghai Yanjing Biotechnology Co., Ltd. (Shanghai, China). The transfection reagent Lipofectamine 2000 was purchased from Fermentas (Vilnius, 
Lithuania). The MTT kit was purchased from Santa Cruz Biotechnolgy (Santa Cruz, CA, USA). p53 antibody was purchased from Beijing Ruixiang Biotechnology Co., Ltd. (Beijing, China). Pharmingen annexin V-fluorescein isothiocyanate was purchased from Beijing Bole Bioscience Development Co. Ltd. (Beijing, China). B-cell lymphoma 2 monoclonal antibody was purchased from Shanghai Shrek Biotechnology Co., Ltd. (Shanghai, China). Caspase-3 monoclonal antibody was purchased from Shanghai Meiji Biotechnology Co. Ltd. (Shanghai, China). The automatic microplate reader was purchased from Labnet International, Inc. (Edison, NJ, USA). The flow cytometer was purchased from Shanghai AoXi Technology Instrument Co., Ltd. (Shanghai, China). The protein electrophoresis apparatus was purchased from Bio-Rad (MEDICA, Berkeley, CA, USA).

\section{Cell culture}

Cell culture was performed using routine laboratory methods. The prostate cancer cells DU-145 and human LNCaP cells were incubated for $72 \mathrm{~h}$ in RPMI 1640 culture medium containing $10 \%$ fetal bovine serum at $37^{\circ} \mathrm{C}$ and $5 \% \mathrm{CO}_{2}$ at a constant temperature. The cells were digested with $25 \%$ pancreatic enzyme, pipetted gently, and passaged as per 1:2 after they were overgrown. The cells were cryopreserved in Dulbecco's modified Eagle medium containing $30 \%$ fetal bovine serum and 10\% dimethyl sulfoxide, and stored in liquid nitrogen.

\section{Transfection}

Prostate cancer cells were incubated with routine RPMI 1640 medium containing $10 \%$ fetal bovine serum and $1 \times 10^{5} \mathrm{U} / \mathrm{L}$ penicillin, digested, passaged with $2.5 \mathrm{~g} / \mathrm{L}$ pancreatic enzyme, and cultured to $90 \%$ confluence growing status. One day before transfection, 2.5 $\mathrm{g} / \mathrm{L}$ pancreatic enzyme was used to digest cells in good growing status to reach $1 \times 10^{8} / \mathrm{L}$. Next, $1 \mathrm{~mL}$ cell culture was added to a 6 -well cell culture plate and incubated overnight. Lipofectamine 2000 was brought to room temperature before transfection. Each transfected cell contained $10 \mu \mathrm{L}$ target plasmid [pcDNA3.1 empty plasmid and pcDNA3.1-p53kipl (G/G) pcDNA3.1- p53kipl (V/V) transfected] and $3 \mu \mathrm{L}$ Lipofectamine 2000 and was cultured at $37^{\circ} \mathrm{C}$ for $12 \mathrm{~h}$. Culture medium containing $10 \%$ fetal bovine serum and $1 \mathrm{~mL} 1 \times 10^{5} \mathrm{U} / \mathrm{L}$ penicillin was added to each well of the culture plate and the plate was incubated for $24 \mathrm{~h}$. PC3 cells and LNCaP cells were divided into 3 groups: PC3-pcDNA, PC3-p53 (G/G), PC3-p53 (V/V); LNCaP-pcDNA, LNCaP-p53 (G/G); and LNCaP-p53 (V/V) (Kim et al., 2013).

\section{Test of transfection efficiency by western blotting}

Transfected prostate cancer cells were placed on ice, washed 3 times with phosphatebuffered saline (PBS), and scraped gently with a cell scraper. The cells were centrifuged at $4000 \mathrm{rpm}(2200 \mathrm{~g})$ for $10 \mathrm{~min}$ and the supernatant was discarded. After addition of $100 \mu \mathrm{L}$ RIPA lysis solution, the cells were placed on ice for $30 \mathrm{~min}$ and then centrifuged at $4{ }^{\circ} \mathrm{C}$ and $12,000 \mathrm{rpm}(10,500 \mathrm{~g})$ for $10 \mathrm{~min}$. Next, $10 \mu \mathrm{L}$ protein, $2 \mathrm{X}$ sodium dodecyl sulfate loading buffer, and $100 \mathrm{mM}$ dithiothreitol were boiled for $5 \mathrm{~min}$, and $50 \mu \mathrm{g}$ protein was subjected to discontinuous sodium dodecyl sulfate-polyacrylamide gel electrophoresis separation. The protein was transferred to the nitrocellulose membrane using wet-type electrotransformation, placed in blocking buffer, and blocked at room temperature twice for $1 \mathrm{~h}$ each. The solution 
was shaken gently overnight at $4^{\circ} \mathrm{C}$ after adding $1 \mu \mathrm{g}$ primary antibody. The membrane was washed with blocking solution for 15 min three times and then shaken gently for $1 \mathrm{~h}$ at room temperature after adding $1 \mu \mathrm{g}$ secondary antibody. The membrane was washed with PBS containing Tween 20 for 15 min twice and then subjected to exposure, development, and y-level scanning (Ren et al., 2013).

\section{MTT colorimetric test}

LNCaP and PC3 cells were inoculated and digested with trypsin, and then $200 \mu \mathrm{L}$ cells were inoculated on a 96-well micro-plate after cell counting. The culture plate was placed in a $\mathrm{CO}_{2}$ incubator and incubated for $24 \mathrm{~h}$. Transfected cells were divided into 8 groups, including PC3 control group, PC3-pcDNA group, PC3-p53 (G/G) group, PC3-p53 $(\mathrm{V} / \mathrm{V})$ group, LNCaP control group, LNCaP-pcDNA group, LNCaP-p53 (G/G), and LNCaPp53 (V/V) group, with 6 wells used for each group. Next, $30 \mu \mathrm{L}$ MTT solution was added to each well. The culture was terminated after continuous incubation in an incubator for $4 \mathrm{~h}$. The supernatant in the well was carefully discarded and $100 \mu \mathrm{L}$ dimethyl sulfoxide was added to each well; the plate was then shaken for $10 \mathrm{~min}$ to allow for sufficient dissolution. Lysis buffer was added to the 96-well micro-plate. The optical density value was determined using an MTT kit at 0, 24, 48, and $72 \mathrm{~h}$.

\section{Cell cycle detection using a flow cytometer}

The cells at 1 and 3 days after transfection were centrifuged and collected; the quantity of cells reached $5 \times 10^{6}$ cells per well. The cells were washed 3 times with PBS. The cells were centrifuged and the supernatant was discarded. The cells were re-suspended in PBS and transferred to a test tube containing $3 \mathrm{~mL}$ pre-cooled absolute ethyl alcohol for preparation with $5 \mathrm{~mL} \mathrm{70 \%} \mathrm{ethanol} \mathrm{solution.} \mathrm{The} \mathrm{solution} \mathrm{was} \mathrm{mixed} \mathrm{well} \mathrm{and} \mathrm{incubated} \mathrm{at} 4^{\circ} \mathrm{C}$ for 12 h. The fixed cells were collected, washed twice with PBS, and centrifuged. The supernatant was discarded and the cells were pipetted gently after addition of PBS. RNase A was added to enable the final concentration to reach $50 \mathrm{mg} / \mathrm{mL}$. The solution was placed in a water bath at $37^{\circ} \mathrm{C}$ for $1 \mathrm{~h}$, after which the sample was digested. The cell suspension was screened through a 300-mesh cell strainer. The cell suspension was placed in a polystyrene tube. Propidium iodide was added to reach a final concentration of $500 \mathrm{mg} / \mathrm{mL}$. After $30 \mathrm{~min}$, the cell cycle was observed using a flow cytometer.

\section{Cell apoptosis detection using a flow cytometer}

The PC3 and LNCaP cells were transfected with the empty plasmid, wild-type pcDNA3.1-p53 (V/V), and mutant pcDNA3.1-p53(G/G). The cells were subjected to staining analysis, washed 2 times with PBS, and re-suspended at a concentration of $1 \times 10^{5}$ cells $/ \mathrm{mL}$ in staining buffer. Next, $10 \mu \mathrm{L}$ cells was pipetted into a test tube and fluorescence-labeled with annexin $\mathrm{V}$ reagent and propidium iodide. The cells were incubated for $15 \mathrm{~min}$ in the dark at room temperature and analyzed using a fast up-flow cytometer after addition of $100 \mu \mathrm{L}$ staining buffer. The cells were collected at 24 and $72 \mathrm{~h}$. The cell apoptosis rate was detected using annexin $\mathrm{V}+$ propidium iodide double-staining flow cytometry. 


\section{Statistical treatment}

The SPSS 12.0 statistical software was used for statistical analysis (SPSS, Inc., Chicago, IL, USA). Measurement data are reported as means \pm standard deviation. Comparison among groups was conducted with the non-paired sample Student $t$-test. $\mathrm{P}<0.05$ was considered to indicate a statistically significant difference.

\section{RESULTS}

\section{Cell culture}

At $72 \mathrm{~h}$ after culture, $\mathrm{LNCaP}$ and $\mathrm{PC} 3$ cells grew to $80 \%$ confluence; the cells showed good growth status. The 2 groups of cells were oblate; the PC3 cells exhibited a cluster shape, while the LNCaP cells were larger than PC3 cells in volume (Figure 1).
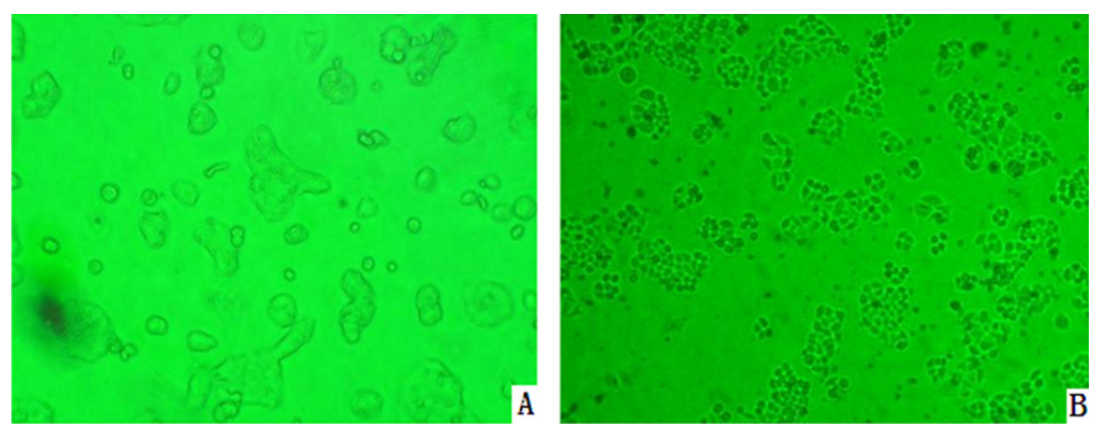

Figure 1. Cellular morphology at $72 \mathrm{~h}$ after cell culture. A. LNCaP cells; B. PC3 cells.

\section{Transfection efficiency}

Western blotting results indicated that the transfection efficiency was satisfactory and the expression level of p53 was extremely low in the control group and empty plasmid group. p53 was highly expressed in the PC3-p53 (G/G), PC3-p53 (V/V), LNCaP-p53 (G/G), and LNCaP-p53 (V/V) groups (Figure 2).
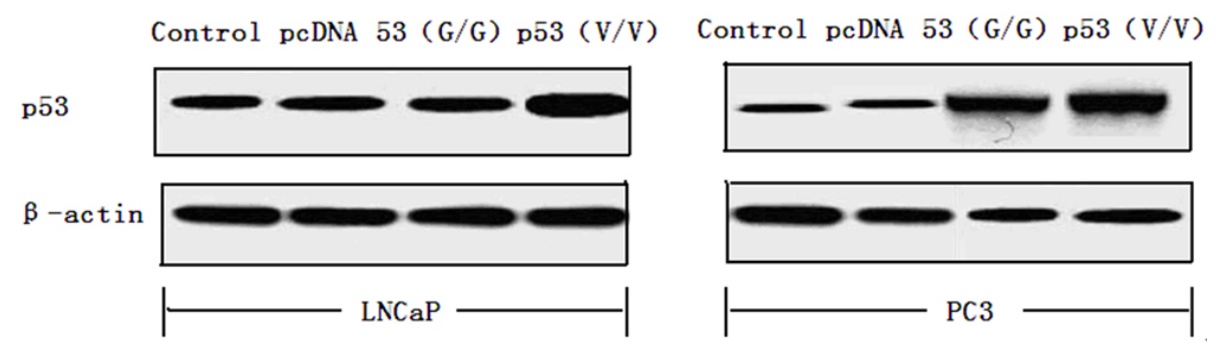

Figure 2. Expression level of p53 in the PC3-p53 (G/G) group, PC3-p53 (V/V) group, LNCaP-p53 (G/G) group, and LNCaP-p53 (V/V) group as determined by western blotting analysis. 


\section{MTT detection results}

The PC3 and LNCaP cells were transfected with empty pcDNA3.1, wild-type pcDNA3.1p53 (V/V), and mutant pcDNA3.1-p53 (G/G). The optical density value was determined at 0 , 24,48 , and $72 \mathrm{~h}$ using an MTT kit and the result showed that at $24 \mathrm{~h}$, compared with the control group, the wild-type pcDNA3.1-p53 (V/V) group and mutant type pcDNA3.1-p53 (G/G) group began to exhibit significantly inhibited cell proliferation $(\mathrm{P}<0.05)$, but the difference between wild-type and mutant type was not significant. At $48 \mathrm{~h}$, differences were observed between the pcDNA3.1-p53 (V/V) group, mutant-type pcDNA3.1-p53 (G/G) group, and control group $(\mathrm{P}<$ $0.05)$; the inhibitory effect of the mutant type was stronger than that of the wild-type group. The difference was more significant at $72 \mathrm{~h}$. There was no significant difference between the PC 3 cell group and LNCaP cell group and their results were similar (Tables 1 and 2).

Table 1. Proliferation of $\mathrm{LNCaP}$ cells not transfected with plasmids (Con), transfected with empty vectors (Blk), and transfected with wild-type pcDNA3.1-p53 (V/V) and the mutant-type pcDNA3.1-p53 (G/G) at 0, 24,48 , and $72 \mathrm{~h}$.

\begin{tabular}{lccrc}
\hline OD490 & o h & $24 \mathrm{~h}$ & $48 \mathrm{~h}$ & $72 \mathrm{~h}$ \\
\hline Con & $0.512 \pm 0.003$ & $0.673 \pm 0.015$ & $0.722 \pm 0.013$ & $0.814 \pm 0.021$ \\
Blk & $0.562 \pm 0.017$ & $0.694 \pm 0.027$ & $0.762 \pm 0.034$ & $0.857 \pm 0.035$ \\
p53 (V/V) & $0.533 \pm 0.024$ & $0.571 \pm 0.019^{*}$ & $0.5171 \pm 0.017^{*}$ & $0.508 \pm 0.017^{*}$ \\
p53 (G/G) & $0.568 \pm 0.016$ & $0.552 \pm 0.031^{*}$ & $0.476 \pm 0.020^{*}$ & $0.415 \pm 0.009^{*}$ \\
\hline
\end{tabular}

Compared with the control group, $* \mathrm{P}<0.05$.

Table 2. Proliferation of PC 3 cells not transfected with plasmids (Con), transfected with empty vectors (Blk), and transfected with wild-type pcDNA3.1-p53 (V/V) and mutant type pcDNA3.1-p5353 (G/G) at 0, 24, 48, and $72 \mathrm{~h}$.

\begin{tabular}{lcccc}
\hline OD490 & $0 \mathrm{~h}$ & $24 \mathrm{~h}$ & $48 \mathrm{~h}$ & $72 \mathrm{~h}$ \\
\hline Con & $0.517 \pm 0.031$ & $0.745 \pm 0.042$ & $0.855 \pm 0.029$ & $0.894 \pm 0.028$ \\
Blk & $0.553 \pm 0.027$ & $0.762 \pm 0.035$ & $0.907 \pm 0.024$ & $0.782 \pm 0.017$ \\
p53 (V/V) & $0.527 \pm 0.033$ & $0.621 \pm 0.030^{*}$ & $0.643 \pm 0.048^{*}$ & $0.548 \pm 0.019^{*}$ \\
p53(G/G) & $0.551 \pm 0.024$ & $0.604 \pm 0.051^{*}$ & $0.536 \pm 0.035^{*}$ & $0.487 \pm 0.026^{*}$ \\
\hline
\end{tabular}

Compared with the control group, $* \mathrm{P}<0.05$.

\section{Cell cycle analysis}

The results of flow cytometry indicated that compared with the cells transfected with vacant plasmids and cells in the control group, after transfection with wild-type pcDNA3.1-p53 (V/V) and mutant-type pcDNA3.1-p53 (G/G), a larger number of PC3 and LNCaP cells were in G0/G1 after transfection with mutant-type pcDNA3.1-p53 (G/G) than after transfection with pcDNA3.1p53 (V/V). There was no significant difference between PC3 and LNCaP cells (Tables 3 and 4).

Table 3. Detection of cycle of the LNCaP cells using flow cytometry.

\begin{tabular}{|c|c|c|c|c|c|c|}
\hline & \multicolumn{3}{|c|}{ At 1 day after $\mathrm{LNCaP}$ cell transfection } & \multicolumn{3}{|c|}{ At 3 days after LNCaP cell transfection } \\
\hline & G0/G1 & $\mathrm{S}$ & $\mathrm{G} 2 / \mathrm{M}$ & $\mathrm{G} 0 / \mathrm{G} 1$ & $\mathrm{~S}$ & $\mathrm{G} 2 / \mathrm{M}$ \\
\hline Control & $52 \%$ & $38 \%$ & $10 \%$ & $55 \%$ & $37 \%$ & $8 \%$ \\
\hline pcDNA & $46 \%$ & $41 \%$ & $13 \%$ & $49 \%$ & $39 \%$ & $12 \%$ \\
\hline $\mathrm{p} 53(\mathrm{~V} / \mathrm{V})$ & $67 \%$ & $19 \%$ & $14 \%$ & $71 \%$ & $16 \%$ & $13 \%$ \\
\hline $\mathrm{p} 53(\mathrm{G} / \mathrm{G})$ & $74 \%$ & $15 \%$ & $11 \%$ & $76 \%$ & $14 \%$ & $10 \%$ \\
\hline
\end{tabular}


Table 4. Detection of cycle of PC3 cells using flow cytometry.

\begin{tabular}{|c|c|c|c|c|c|c|}
\hline & \multicolumn{3}{|c|}{ At 1 day after PC 3 cell transfection } & \multicolumn{3}{|c|}{ At 3 days after PC 3 cell transfection } \\
\hline & $\mathrm{G} 0 / \mathrm{G} 1$ & $S$ & $\mathrm{G} 2 / \mathrm{M}$ & $\mathrm{G} 0 / \mathrm{G} 1$ & $S$ & G2/M \\
\hline Control & $54 \%$ & $41 \%$ & $5 \%$ & $55 \%$ & $43 \%$ & $2 \%$ \\
\hline pcDNA & $50 \%$ & $44 \%$ & $6 \%$ & $52 \%$ & $46 \%$ & $2 \%$ \\
\hline $\mathrm{p} 53(\mathrm{~V} / \mathrm{V})$ & $77 \%$ & $20 \%$ & $3 \%$ & $84 \%$ & $15 \%$ & $1 \%$ \\
\hline $\mathrm{p} 53(\mathrm{G} / \mathrm{G})$ & $82 \%$ & $16 \%$ & $2 \%$ & $89 \%$ & $10 \%$ & $1 \%$ \\
\hline
\end{tabular}

\section{Apoptosis detection}

Compared with the control group, the wild-type pcDNA3.1-p53 (V/V) and mutanttype pcDNA3.1-p53 (G/G) showed increased rates of PC3 and LNCaP cell apoptosis, while at $72 \mathrm{~h}$, the mutant-type pcDNA3.1-p53 (G/G) was more likely to cause significant cell apoptosis compared with wild-type pcDNA3.1-p53 (V/V) (Figures 3 and 4).
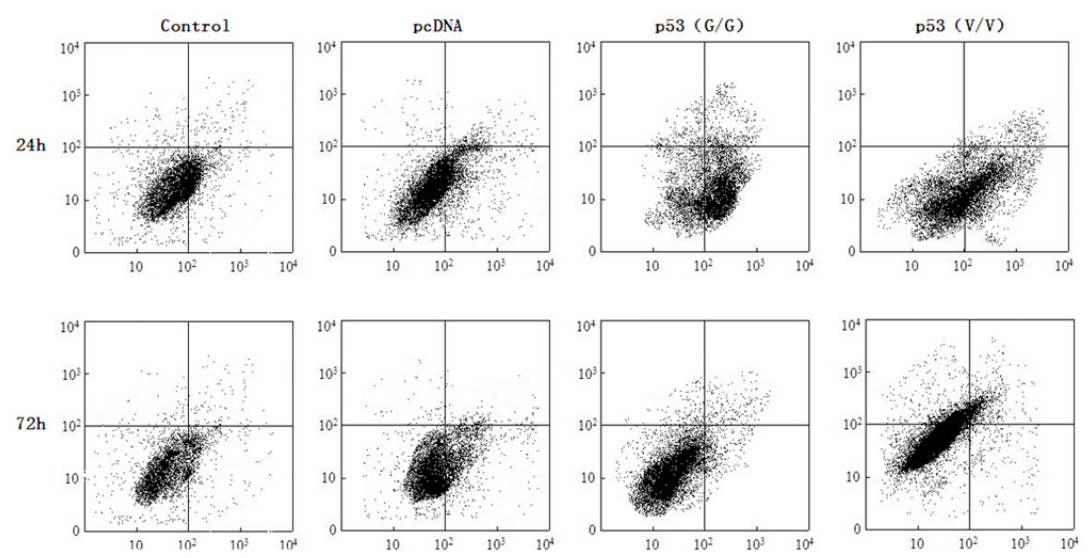

Figure 3. Apoptosis of prostate cancer LNCaP cells transfected with different plasmids at 24 and $72 \mathrm{~h}$.
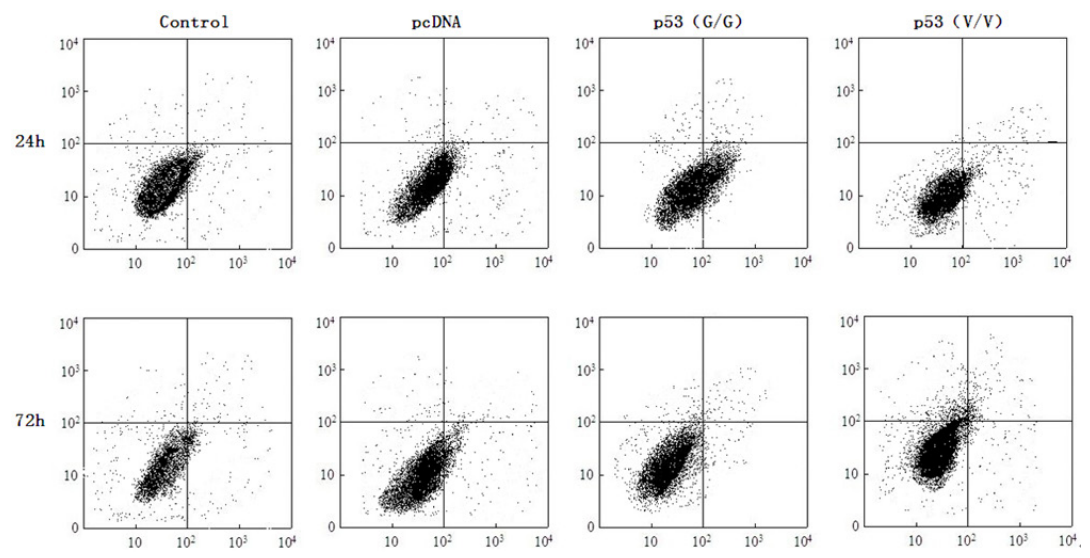

Figure 4. Apoptosis of prostate cancer PC 3 cells transfected with different plasmids at 24 and $72 \mathrm{~h}$. 


\section{DISCUSSION}

Currently, prostate cancer morbidity is increasing in China. Prostate cancer in the progressive stage as well as metastatic prostate cancer are primarily treated using androgen deprivation therapy. Currently, various types of androgen deprivation therapies are achieved by lowering the androgen levels and activating the capacity of its receptor, including lowering the level of androgen in the blood circulation and preventing the androgen from binding to its receptor (Tan et al., 2012). Most patients show a good reaction to androgen deprivation therapy initially, but many of these patients inevitably experience an increase in circulating blood prostate-specific antigen and ineffective anti-androgen treatment after 18-24 months. The disease in these patients is then changed into HRPC. HRPC causes approximately 42,000 patient deaths (Gupta et al., 2012). The progression-free survival time and total survival time of metastatic prostatic cancer patients who received different types of androgen deprivation therapy are 12-20 and 24-36 months, respectively (Chappell et al., 2012; Katkoori et al., 2013). In recent years, clinical researchers have found that systemic chemotherapy increases the survival rate and survival quality of patients with HRPC (Bishayee et al., 2013). However, in general, there is no effective method for treating HRPC.

The $p 53$ gene is a cancer-suppressor gene located on human chromosome 17p13.1, which encodes the 53-kDa intranuclear phosphorylated protein composed of 393 amino acids known as the $\mathrm{p} 53$ protein (Tan et al., 2013). The $p 53$ gene is a negative regulatory factor in the cell growth cycle and is associated with important biological functions such as cell cycle regulation, DNA repair, cell differentiation, and cell apoptosis, among others (Liu et al., 2013). The $p 53$ gene and its products are divided into wild type and mutant type. The wild-type p53 protein is extremely unstable, with a half-life period of only several minutes, and shows transactivation and broad-spectrum tumor inhibition functions. The stability of mutant-type p53 protein increases, extending the half-life, which can be detected using immunohistochemical methods (Fichtenbaum et al., 2012). The $p 53$ gene mutation (deletion) is a common event in human tumors and is associated with tumor occurrence and progress. Overexpression of p53 is thought to be associated with tumor metastasis, relapse, and poor prognosis. The $p 53$ gene mutation occurs in more than $50 \%$ of all malignant tumors (Mi et al., 2012). The protein coded by this gene is a transcription factor that controls initiation of the cell cycle. Numerous signals associated with cellular health are delivered to the p53 protein (Xiaowen and Yi, 2012). If the cell is damaged and remains unrepaired, the p53 protein can participate in the initiation process to kill the cell by cell apoptosis (Lin et al., 2012). Cells carrying deficient p53 do not have this control and even divide under adverse conditions (Heckman et al., 2012). Similar to other tumor-inhibiting factors, the $p 53$ gene plays a role in slowing or monitoring cell division under normal conditions. The intracellular $p 53$ gene can detect the degree of DNA variation, and the gene will promote cell self-repair if the variation is minor; however, p53 will induce cell apoptosis if the DNA variation degree is major (Saidi et al., 2011).

In normal adult prostate tissue, the mRNA of $p 53$ is primarily concentrated in acinar cells in the basilar region of the prostate, while the p 53 protein is primarily present in terminally differentiated and secretory cells (Madani et al., 2011). In prostate tissue blocked by androgen, the expression level of the p53 protein decreases and the population of prostate cells expressing keratin of basal cells and specific cells increases significantly. However, prostate cancer cells lacking p53 are considered to have a potential temporary proliferation subregion (Li et al., 2011). Decreased expression of p53 eliminates cell cycle arrest. Thus, p53 expres- 
sion dysregulation may be an early event that occurs before the occurrence of prostate cancer and finally makes prostate cells particularly vulnerable to proliferation induced by androgen (Cai et al., 2012).

Cell proliferation requires stimulation from extracellular signals. After stimulation by extracellular signals, cells in the G1 stage exhibit 2 main properties. First, the cells enter stage G0 after being stimulated by anti-proliferation signals. Second, the cells enter stage $\mathrm{S}$ through stage G1 after being stimulated by mitogen; cell division will begin, the number of cells increases, and the cells proliferate (Won et al., 2012). In tumor tissues, cells proliferate at a rate that is considerably higher than that of normal cells. Many studies have found that a decrease in p53 level will increase the rate of cell proliferation when the cells receive cancerous growth signals. This phenomenon has been demonstrated in urinary bladder cancer, breast cancer, and prostate cancer, among others (Vlachostergios et al., 2012). Our experimental results also showed that the over-expression of p53 protein in prostate cancer cells can lower the rate of cell proliferation, possibly because p53 protein reduces the progression rate of stage G1. More importantly, we observed a difference in the proliferation inhibition of prostate cancer cells between the wild-type and mutant-type p53; the mutant type showed a stronger inhibitory effect. This is likely because the degradation process of the mutant-type p53 protein was extended, thus strengthening the proliferation capacity of suppressor cells. A low rate of cell proliferation generally results when the cell cycle is affected (Kim et al., 2012).

Cell apoptosis and cell proliferation are the most basic life activities of cells. The balance between both is an important factor that maintains normal development and homeostasis in organisms (Gan et al., 2011). Apoptosis inhibition is a universal characteristic of cancer cells, which can improve their viability; however, the specific mechanism remains unclear. Numerous signal pathways are associated with cell apoptosis, among which the most important are B-cell lymphoma 2, B-cell lymphoma-associated X protein, and caspase-3 (Zhang et al., 2011). The relationship between p53 and apoptosis has been widely studied. (Tang et al., 2011) proposed that transforming the $p 53$ gene into multiple cell lines could cause apoptosis. A previous study found that over-expression of p53 in many tumors can lead to apoptosis (Suh et al., 2011). This is also consistent with our experimental results; over-expression of p53 in prostate cancer promoted the apoptosis of prostate cancer cells. In addition, our experimental results indicated that the mutant-type p53 had a stronger capacity to induce apoptosis than did the wild-type $\mathrm{p} 53$. Thus, $p 53$ gene polymorphisms affected the capacity of $\mathrm{p} 53$ to induce apoptosis, but this change showed no significant difference between PC3 and LNCaP cells.

\section{REFERENCES}

Amir S, Ma AH, Shi XB, Xue L, et al. (2013). Oncomir miR-125b suppresses p14(ARF) to modulate p53-dependent and p53-independent apoptosis in prostate cancer. PLoS One 8: 1064-1068.

Bishayee K, Chakraborty D, Ghosh S, Boujedaini N, et al. (2013). Lycopodine triggers apoptosis by modulating 5-lipoxygenase, and depolarizing mitochondrial membrane potential in androgen sensitive and refractory prostate cancer cells without modulating p53 activity: signaling cascade and drug-DNA interaction. Eur. J. Pharmacol. 698: 110-121.

Cai C, Hsieh CL, Gao S, Kannan A, et al. (2012). Soluble guanylyl cyclase alpha1 and p53 cytoplasmic sequestration and down-regulation in prostate cancer. Mol. Endocrinol. 26: 292-307.

Chappell WH, Lehmann BD, Terrian DM, Abrams SL, et al. (2012). p53 expression controls prostate cancer sensitivity to chemotherapy and the MDM2 inhibitor Nutlin-3. Cell Cycle 11: 4579-4588.

De Luca P, Moiola CP, Zalazar F, Gardner K, et al. (2013). BRCA1 and p53 regulate critical prostate cancer pathways. Prostate Cancer Prostatic Dis. 16: 233-238. 
Fichtenbaum EJ, Marsh WL Jr and Zynger DL (2012). CK5, CK5/6, and double-stains CK7/CK5 and p53/CK5 discriminate in situ vs invasive urothelial cancer in the prostate. Am. J. Clin. Pathol. 138: 190-197.

Gan L, Wang J, Xu H and Yang X (2011). Resistance to docetaxel-induced apoptosis in prostate cancer cells by p38/p53/ p21 signaling. Prostate 71: 1158-1166.

Gupta K, Thakur VS, Bhaskaran N, Nawab A, et al. (2012). Green tea polyphenols induce p53-dependent and p53independent apoptosis in prostate cancer cells through two distinct mechanisms. PLoS One 7: 2572-2578.

Heckman MG, Parker AS, Wu KJ, Hilton TW, et al. (2012). Evaluation of MDM2, p16, and p53 staining levels as biomarkers of biochemical recurrence following salvage radiation therapy for recurrent prostate cancer. Prostate 72 : $1757-1766$.

Katkoori VR, Manne K, Vital-Reyes VS, Rodríguez-Burford C, et al. (2013). Selective COX-2 inhibitor (celecoxib) decreases cellular growth in prostate cancer cell lines independent of p53. Biotech. Histochem. 88: 38-46.

Kim J, Roh M, Doubinskaia I, Algarroba GN, et al. (2012). A mouse model of heterogeneous, c-MYC-initiated prostate cancer with loss of Pten and p53. Oncogene 31: 322-332.

Kim JY, Chung JY, Lee SG, Kim YJ, et al. (2013). p53 interferes with microtubule-stabilizing agent-induced apoptosis in prostate and colorectal cancer cells. Int. J. Mol. Med. 31: 1388-1394.

Li MS, Liu JL, Wu Y, Wang P, et al. (2011). Meta-analysis demonstrates no association between p53 codon 72 polymorphism and prostate cancer risk. Genet. Mol. Res. 10: 2924-2933.

Lin VC, Tsai YC, Lin JN, Fan LL, et al. (2012). Activation of AMPK by pterostilbene suppresses lipogenesis and cellcycle progression in 533 positive and negative human prostate cancer cells. J. Agric. Food Chem. 60: 6399-6407.

Liu C, Zhu Y, Lou W, Nadiminty N, et al. (2013). Functional p53 determines docetaxel sensitivity in prostate cancer cells. Prostate 73: 418-427.

Madani SH, Ameli S, Khazaei S, Kanani M, et al. (2011). Frequency of Ki-67 (MIB-1) and P53 expressions among patients with prostate cancer. Indian J. Pathol. Microbiol. 54: 688-691.

Mi YY, Zhu LJ, You XM and Wu S (2012). Clarification of data for a meta-analysis: p53 codon 72 polymorphism and prostate cancer risk. Genet. Mol. Res. 11: 1958-1959.

Ren D, Wang M, Guo W, Zhao X, et al. (2013). Wild-type p53 suppresses the epithelial-mesenchymal transition and stemness in PC-3 prostate cancer cells by modulating miR145. Int. J. Oncol. 42: 1473-1481.

Saidi S, Georgiev V, Stavridis S, Penev M, et al. (2011). Evaluation of the value of p53 protein expression in the extracapsular extension of prostate cancer. Prilozi 32: 213-220.

Shin S, Jing K, Jeong S, Kim N, et al. (2013). The omega-3 polyunsaturated fatty acid DHA induces simultaneous apoptosis and autophagy via mitochondrial ROS-mediated Akt-mTOR signaling in prostate cancer cells expressing mutant p53. Biomed. Res. Int. 42: 671-674.

Simone CB, John-Aryankalayil M, Palayoor ST, Makinde AY, et al. (2013). mRNA expression profiles for prostate cancer following fractionated irradiation are influenced by p53 status. Transl. Oncol. 6: 573-585.

Suh SO, Chen Y, Zaman MS, Hirata H, et al. (2011). MicroRNA-145 is regulated by DNA methylation and p53 gene mutation in prostate cancer. Carcinogenesis 32: 772-728.

Tan D, Tan S, Zhang J, Tang P, et al. (2013). Histone trimethylation of the p53 gene by expression of a constitutively active prolactin receptor in prostate cancer cells. Chin. J. Physiol. 56: 524-528.

Tan J, Chen B, He L, Tang Y, et al. (2012). Anacardic acid (6-pentadecylsalicylic acid) induces apoptosis of prostate cancer cells through inhibition of androgen receptor and activation of p53 signaling. Chin. J. Cancer Res. 24: 275-283.

Tang NY, Huang YT, Yu CS, Ko YC, et al. (2011). Phenethyl isothiocyanate (PEITC) promotes G2/M phase arrest via p53 expression and induces apoptosis through caspase- and mitochondria-dependent signaling pathways in human prostate cancer DU 145 cells. Anticancer Res. 31: 1691-1702.

Vlachostergios PJ, Karasavvidou F, Patrikidou A, Voutsadakis IA, et al. (2012). p53 and cyclooxygenase-2 expression are directly associated with cyclin D1 expression in radical prostatectomy specimens of patients with hormone-naive prostate cancer. Pathol. Oncol. Res. 18: 245-252.

Wang Y, Zhang YX, Kong CZ, Zhang Z, et al. (2013). Loss of P53 facilitates invasion and metastasis of prostate cancer cells. Mol. Cell. Biochem. 384: 121-127.

Won SH, Lee HJ, Jeong SJ, Lü J, et al. (2012). Activation of p53 signaling and inhibition of androgen receptor mediate tanshinone IIA induced G1 arrest in LNCaP prostate cancer cells. Phytother. Res. 26: 669-674.

Xiaowen H and Yi S (2012). Triptolide sensitizes TRAIL-induced apoptosis in prostate cancer cells via p53-mediated DR5 up-regulation. Mol. Biol. Rep. 39: 8763-8770.

Zhang B, Xiao HJ, Chen J, Tao X, et al. (2011). Inhibitory member of the apoptosis-stimulating protein of p53 (ASPP) family promotes growth and tumorigenesis in human p53-deficient prostate cancer cells. Prostate Cancer Prostatic Dis. 14: 219-224. 